NASA TIMX: 55859

\title{
CIRCULATION FEATURES OF THE STRATOSPHERE DERIVED FROM RADIOMETRIC TEMPERATURE MEASUREMENTS WITH THE TIROS VII SATELLITE
}

\author{
BY \\ JAMES S. KENNEDY \\ WILLIAM NORDBERG
}

GPO PRICE \$

CFStI PRICE(S) $\$$

$\mathrm{Har}$ sopy $(\mathrm{HC})$ 3,00 MARCH 1967

Microfiche (MF)

f 653 July 65

NASA

GODDARD SPACE FLIGHT CENTER GREENBELT, MARYLAND

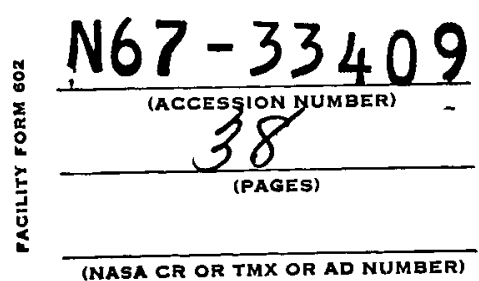

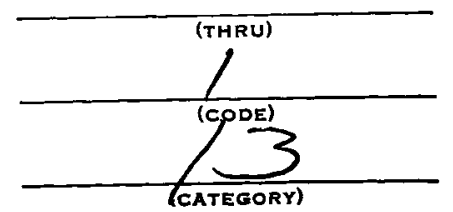




\title{
CIRCULATION FEATURES OF THE STRATOSPHERE DERIVED FROM RADIOMETRIC TEMPERATURE MEASUREMENTS WITH THE TIROS VII SATELLITE
}

\author{
by \\ James S. Kennedy \\ U. S. Air Force \\ Air Weather Service \\ Washington, D.C.* \\ and \\ William Nordberg \\ NASA/Goddard Space Flight Center \\ Greenbelt, Maryland
}

*This work was performed while temporarily with the NASA Goddard Space Flight Center

Goddard Space Flight Center

Greenbelt, Maryland 


\begin{abstract}
Measurements of radiation emitted by atmospheric carbon dioxide at 15 microns were performed with the TIROS VII satellite. These measurements describe temperature patterns in the lower stratosphere. Temperature patterns covering a "quasi-global" zone $\left(65^{\circ} \mathrm{N}-\right.$ $65^{\circ} \mathrm{S}$ ) are investigated for the period June 1963-November 1964. The satellite observations reveal large scale circulation features of the stratosphere, particularly during the late winter breakdown periods.

The salient feature in the Southern Hemisphere, during both late winters of 1963 and 1964 , is the occurrence of a warm cell in the vicinity of Australia. This implies a deflection of the initially circumpolar vortex towards the eastern Pacific. In the Northern Hemisphere, winter is characterized by the well known warm cell over the Aleutian Islands with the vortex displaced towards the Atlantic. The Australian and North Pacific warm cells form the nucleus of the springtime warmings which then spread zonally over the entire Southern and Northern Hemisphere, respectively.
\end{abstract}

A quantitative Fourier Analysis of the temperature variance along high latitude circles leads to the conclusion that there is considerable transport of ozone and heat by horizontal eddies in both Hemispheres during winter. Disturbances in the zonal circulation during that period are predominantly of wave number one. During summer wave number zero prevails. 


\section{INTRODUCTION}

Observations of global stratospheric temperature fields presented here are based on satellite measurements of the radiant emittance of the atmosphere in the spectral interval $14.8-15.5$ microns. These measurements were obtained by TIROS VII continuously during June 1963 to November 1964. The radiometer consisted of a thermistor bolometer, filters, light gathering mirrors and lenses, and associated electronics. The instantaneous field of view was approximately $5 \times 5$ degrees. During a period of 12 hours, which corresponds to 14 consecutive orbits, the instrument scanned contiguously over the entire zone of the Earth between $65^{\circ} \mathrm{N}$ and $65^{\circ} \mathrm{S}$. Thus, theoretically, radiation patterns over this "quasi global" zone were mapped by the satellite every 12 hours. Practically, however, the time interval during which full coverage was achieved ranged over several days because measurements could not be transmitted to the ground for each and every full orbit. Also, the spatial resolution of the measurements presented here is considerably coarser than that theoretically possible: Each instantaneous radiation measurement with a field of view $5 \times 5$ degrees corresponded to an area of $50 \times 50 \mathrm{~km}$ on the surface of the Earth. However, the radiometric accuracy of such a measurement when converted to equivalent black body temperature was generally poorer than $\pm 5^{\circ} \mathrm{C}$. Averaging many hundred measurements over larger areas $\left(5^{\circ}\right.$ latitude $\times 5^{\circ}$ longitude near the equator and $2.5^{\circ}$ latitude $\times 5^{\circ}$ longitude near $60^{\circ}$ ) and time periods of 10 days resulted in nearly full coverage of the "quasi globe" with satisfactory accuracy 
(better than $\pm 1^{\circ} \mathrm{C}$ ). There were two consistent gaps in the observations: one over the southern tip of South America, the other over Central Siberia (near $\left.110^{\circ} \mathrm{E}\right)$. These gaps were due to the fact that the orbits passing over these regions were always outside the communication range of data acquisition stations and observations over these regions could, therefore, never be transmitted to the ground. In the data presented here observations from adjacent areas were linearly extrapolated to cover these gaps.

Since the major features of stratospheric behavior are known to occur on a scale of thousands of kilometers (Teweles 1963) and over periods of several weeks (Boville 1960) the time and space averaging applied to our satellite measurements should not materially affect the information to be derived from these measurements. A detailed description of the instrument construction, the orbital geometry of TIROS VII and the characteristics of the radiometer was published elsewhere (Staff Members 1964). Preliminary results were discussed by Nord-

berg et. al., (1965) and a complete presentation of the "quasi-global" temperature fields were given by Kennedy (1966).

\section{RADIATION MEASUREMENTS AND STRATOSPHERIC TEMPERATURE PATTERNS}

The radiant emittances measured by the satellite sensor in this spectral interval (14.8 - 15.5 microns) are primarily due to thermal emission in the vibration-rotation band of carbon dioxide. It is assumed that carbon dioxide is distributed throughout the upper troposphere and stratosphere uniformly and at 
a constant mixing ratio. Also, assuming a typical temperature profile of the troposphere and stratosphere such as that given by the U. S. Standard Atmosphere (1962), one may compute for any given height interval in the atmosphere the radiant emittance which is transmitted to the satellite within this spectral interval. The result of such computation is shown, on a relative scale, in Figure 1. The curve in Figure 1 demonstrates that more than 90 percent of the total radiation sensed by the satellite is emitted by the atmosphere above $10 \mathrm{~km}$. More than 70 percent of that total radiation is emitted at heights between 10 and $30 \mathrm{~km}$. The weighting curve (Fig. 1) has a maximum near the $20 \mathrm{~km}$ level. Thus, if the measured radiant emittances are converted to equivalent blackbody temperatures, they can be generally interpreted as atmospheric temperatures averaged over the height range from 10 to $30 \mathrm{~km}(50-10 \mathrm{mb})$. The "weights" assigned to each height level in such an averaging process would correspond to the relative values given by the curve in Figure 1. Equivalent blackbody temperature is defined here as the temperature of an isothermal blackbody filling the field of view of the sensor (as in the laboratory calibration) which would cause the same response from the radiometer as does the general non-Planckian spectral distribution of the radiation emerging from the top of the atmosphere in the direction of the satellite.

Since a vertically weighted mean temperature does not easily fit into the framework of existing conventional measurements the absolute values of equivalent blackbody temperatures cannot be interpreted very readily as a meteorological 
measurement. At extratropical latitudes, where the atmospheric temperature between 10 and $30 \mathrm{~km}$ is quite constant, equivalent blackbody temperatures correspond more closely to the actual temperature than in the tropics where the temperature varies greatly in this height range. Global, horizontal patterns of these temperatures are, however, very descriptive of large scale circulation features in the lower stratosphere. All discussions of temperature flelds and circulation patterns derived from these measurements will therefore be based on the observed variation of equivalent blackbody temperatures with time and space.

It must be noted that the weighting curve shown in Figure 1 holds strictly only for the postulated temperature profile (U.S. Standard Atmosphere 1962). A slightly altered weighting curve will result from other typical temperature profiles. However, it has been shown (Nordberg et. al., 1965) that variations in the weighting curves due to variations in the temperature profiles expected to exist at various latitudes and seasons are small. Figure 1 also indicates that some radiation is observed from the lower atmosphere $(5-10 \mathrm{~km})$. In cases where an opaque cloud deck at the tropopause obscures the radiation from the underlying warmer atmosphere derived equivalent blackbody temperatures will be colder by about $5^{\circ} \mathrm{C}$ than in cases where there are no clouds. This effect will be much more pronounced in the tropics than at high latitudes. But, even in the tropics, such temperature variation due to cloud cover will be minimized in the relatively large area and long time averages presented here. Thus, global 
patterns of observed equivalent blackbody temperatures at $14.8-15.5$ microns are highly indicative of the actual temperature of the lower and middle stratosphere.

\section{SYNOPTIC PRESENTATION OF EQUIVALENT BLACKBODY TEMPERATURE FIELDS AND INFERRED CIRCULATION}

Figures 2 through 6 are typical examples of the temperature patterns observed in the $60^{\circ} \mathrm{N}$ to $60^{\circ} \mathrm{S}$ "quasi-global" zone during the annual cycle from June 1963 to July 1964. Of some seventy such maps presented by Kennedy (1966) these were selected to illustrate how the satellite observations describe the morphology of the warm and cold air masses established in the respective summer and winter Hemispheres. Especially in the vast oceanic and Southern Hemisphere areas, where observations were lacking thus far, the isotherm patterns shown in Figures 2 through 6 can be used to obtain a better picture of the major circulation patterns in the stratosphere: the summer polar anticyclones and the winter polar vortices. These are quite apparent in Figures 2 and 3 during the June 1963 and 1964 solstices. In both years the warm core is centered over the North polar cap, the cold core over the South polar cap. A significant deviation in the symetry of the rather closely spaced isotherms around the South Pole occurs over the central South Pacific. In 1963 (Figure 2) a ridge of warm air (high pressure) extends to high latitudes southeast of Australia and over New Zealand while cold air (low pressure) penetrates to low latitudes over the eastern Pacific Ocean, suggesting anticyclonic circulation 
over Australia. Differences of about $6^{\circ} \mathrm{C}$ in equivalent blackbody temperatures along latitude circles are observed between the western and eastern South $\mathrm{Pa}$ cific. This asymmetry was observed during both the 1963 and 1964 (Fig. 3) Southern Hemisphere winters and was observed again with greater detail in the south polar region during 1966 with the Nimbus II satellite (Nordberg 1966). During 1963 the asymmetry becomes most pronounced in September (Fig. 4) when the vortex begins to break down. At that time the warm air ridge spreads considerably westward so that warm air occupies the entire southern Indian and Atlantic Oceans, while cold air still dominates the South Pacific. The equivalent blackbody temperature difference between the Pacific and the Indian Oceans along $60^{\circ} \mathrm{S}$ is almost $20^{\circ} \mathrm{C}$. This is greater than the $16^{\circ} \mathrm{C}$ temperature difference between $30^{\circ} \mathrm{S}$ and $60^{\circ} \mathrm{S}$ during the June solstice (Fig. 2). These warm cells in the Southern Hemisphere are presumably a sign of subsidence induced by tropospheric events and may explain the ozone maximum found near $50^{\circ} \mathrm{S}$ in September (Hare and Boville, 1966).

In the Northern Hemisphere, where the temperature differences between $30^{\circ} \mathrm{N}$ and $60^{\circ} \mathrm{N}$ during the summer solstice is only $10^{\circ} \mathrm{C}$ (Fig. 2), there are practically no temperature gradients with latitude or longitude during the autumnal equinox (Fig. 4). This indicates the absence of any major circulation during that period. Northern Hemisphere isotherm patterns, and consequently circulation patterns, become gradually organized during October. But, during this entire process these isotherms do not even approximately follow latitude 
circles. This asymmetry persists with varying intensity during the entire winter and is shown in Fig. 5 for the period immediately before the winter solstice when it is most intense. The center of the north polar cold air vortex is consistently displaced toward the Atlantic and Europe while much warmer air and associated anticyclonic circulation prevail over the Pacific Ocean and eastern Siberia. During most of the winter the maximum equivalent blackbody temperature difference along $60^{\circ} \mathrm{N}$ is about $22^{\circ} \mathrm{C}$. This temperature difference is considerably greater than the temperature difference between $30^{\circ} \mathrm{N}$ and $60^{\circ} \mathrm{N}$ observed during most of the winter. Only one major midwinter stratospheric warming occurred during the $1963 / 1964$ winter. It occurred on 22 January and is quite apparent in the satellite observed temperature fields (Fig. 6). The warming is situated over southwestern Asia and results in a tightening of the isotherms over eastern Europe. Because of the gap in the satellite observations over central Siberia and the absence of conventional data, it is difficult to determine if the sudden warming is connected in the east with the warm air mass which, at the time, spreads from Siberia to central North America. A detailed account of the observation of this warming by TIROS VII was given by Nordberg et. al. (1965). By mid February all effects of this transient warming have disappeared and temperature fields similar to mid December are established.

During the entire summer in the Southern Hemisphere isotherms run fairly parallel to latitude circles. Temperature gradients with latitude are greater in the Southern Hemisphere than they were in the previous Northern Hemisphere 
summer. Temperature differences between $30^{\circ} \mathrm{S}$ and $60^{\circ} \mathrm{S}$ during December through February are generally 12 to $14^{\circ} \mathrm{C}$, they were about $10^{\circ} \mathrm{C}$ in the Northern Hemisphere. This is because temperatures in the tropics are considerably lower during December/January than they are during June/July, but at high latitudes maximum temperatures are nearly the same in the Southern and Northern Hemispheres (Fig. 7). We have not been able to explain the exact reason for this large annual temperature variation in the tropics. However, qualitatively, one may argue that the much more zonally oriented circulation in the Southern Hemisphere winter suppresses interaction between the tropics and high latitudes more strongly than during the Northern Hemisphere winter when stronger meridinal circulation results in more interaction between the tropics and high latitudes. Such interaction could result in maximum cooling of the tropical atmosphere during December and January while cooling would be much less when the exchange with the winter Hemisphere is essentially blocked by the zonal circulation around the South Pole. This speculation is substantiated by the almost perfect phase relationship between the high latitude Northern Hemisphere and tropical temperature curves in Figure 7. The $180^{\circ}$ phase lag in Figure 7 between the high latitude Northern and Southern Hemisphere curves indicates that the overall temperature cycle in the stratosphere is strictly controlled by solar elevation. Note the almost identical zonal average temperatures at high Northern and Southern latitudes and in the tropics during the equinoxes. The difference in the amplitudes of the high latitude curves in the two Hemispheres 
in winter indicates that the magnitude of the temperatures in the stratosphere are strongly influenced by probably both radiative exchange with the surface and lower atmosphere, and eddy transfer of energy within the stratosphere. The warm anticyclone over the North Pacific is obviously responsible for the fact that zonal average temperatures between $40-65^{\circ} \mathrm{N}$ are $4-6^{\circ} \mathrm{C}$ higher in December/January than corresponding temperatures between $40-65^{\circ} \mathrm{S}$ during June/July. The almost equal amplitudes of the two high latitude curves in Figure 7 during summer indicate that such effects are of lesser consequence in summer.

The complete and continuous maps of temperature fields presented by Kennedy (1966) permit an analysis of the development of the final stratospheric warmings in the Northern and Southern Hemispheres during March 1964 and September 1963, respectively. The essence of this analysis is illustrated in Figure 8. The Northern Hemisphere warming of 1964 was clearly an example of the asymmetric or single source type as opposed to the symmetric or double source type (Wilson and Godson, 1963). The warm cell, located over the Kamchatka Peninsula in mid-February spread eastward until early March, then expanded both eastward and westward and presumably poleward, displacing the remnants of the cold polar vortex towards central Europe, where the cyclonic vortex dissipated in early April. The final warming occurred first over Canada, then Eastern Siberia, and last over Europe. The curves of Fig. 8 show that the entire transformation proceeded quite smoothly and steadily. 
The final warming of the Southern Hemisphere (Fig. 9) was also of the single source, type which Palmer and Taylor (1960) suggest is the rule in the Southern Hemisphere. Closed warm cells appeared south of Australia at latitude 40 to 50 degrees South in late August and shifted westward and southward in September to the south Central Indian Ocean. The warm cells increased in area in a series of surges, finally displacing the cold polar vortex towards South America in late October where dissipation occurred. The end of the final warming occurred well after the vernal equinox.

\section{HORIZONTAL EDDY ACTIVITY IN BOTH HEMISPHERES ILLUSTRATED BY THE VARIANCE IN EQUIVALENT BLACKBODY TEMPERATURES}

A more quantitative comparison of the Northern and Southern Hemisphere stratospheres may be made by examining the variance of temperature around latitude circles. Emphasis is placed on the behavior of the thermal patterns at the higher latitudes in each Hemisphere primarily because of the more significant activity in these regions. The east-west temperature variance provides first a measure of the potential energy available for conversion into eddy kinetic energy (Lorent, 1955). Secondly, it provides at least a qualitative estimate of the degree of horizontal eddy activity and the meridional flux of enthalpy by quasi-horizontal eddies. The actual transport depends, of course, on the covariance of temperature and the meridional wind component. However, a large variance of temperature makes possible a large wind temperature 
covariance and such large variances can be derived from the satellite observed temperature patterns which are the only data at our disposal on a global scale. In this derivation we are obviously relying on previous studies of the stratosphere to judge the magnitude and even the sign of the wind-temperature covariance (Newell, 1965; Oort, 1963; Hare and Boville, 1966).

The temperature along a particular latitude is described by an equally spaced set of 72 values as a single valued periodic function. This function is expressed in a Fourier series of the form,

where

$$
T(\lambda)=[T]+\sum_{n=1}^{36}\left(A_{n} \cos n \lambda+b_{n} \sin n \lambda\right)
$$

$$
\begin{gathered}
A_{n}=\frac{1}{36} \sum_{i=1}^{72} T\left(\lambda_{i}\right) \cos (2 \pi n i / 72) \\
b_{n}=\frac{1}{36} \sum_{i=1}^{72} T\left(\lambda_{i}\right) \sin (2 \pi \mathrm{ni} / 72) \\
T=\text { temperature in deg. } \mathrm{K} . \\
\lambda=\text { longitude } \\
{[T]=\text { zonal mean temperature }} \\
\mathrm{n}=\text { zonal wave number }
\end{gathered}
$$

To express the thermal waves in terms of amplitude and phase, equation (1) may be rearranged to give,

$$
T(\lambda)=[T]+\sum_{n=1}^{36} c_{n} \cos \left(n \lambda-\phi_{n}\right)
$$


where

$$
C_{n}=\left(A_{n}^{2}+b_{n}^{2}\right)^{1 / 2}, n=1-35
$$

amplitude of $n^{\text {th }}$ zonal harmonic

$$
\begin{aligned}
& C_{36}=\left(A_{36} / 2\right) \\
& \phi_{n}=\arctan \frac{b_{n}}{a_{n}}
\end{aligned}
$$

phase of $n^{\text {th }}$ zonal harmonic

The variance due to an individual harmonic is equal to $C_{n}^{2} / 2$ and the total variance of temperature, $\sigma_{\mathrm{T}}^{2}$, is given by

$$
\sigma_{T}^{2}=\sum_{n=1}^{35} C_{n}^{2} / 2+C_{36}^{2}
$$

Use of the Fourier series makes possible the study of the development of significant harmonics in both amplitude and phase. The rationale for the expression of meteorological quantitiés in the domain of wave number is well covered by Saltzman (1957). The top curve in Figure 10 is the zonal mean temperature difference between two northerly latitude circles and serves to indicate the progression of the seasons for the warm polar anticyclone of summer to the cold cyclonic vortex of winter. The center curves show the total temperature variance and that portion due to wave number one for a typical high latitude: $52.3 \mathrm{~N}$. The lower curve shows the longitudinal position of the ridge of thermal wave number one for latitude $52.3 \mathrm{~N}$. 
The variance curves show an absence of wave perturbations from the summer solstice to the autumnal equinox. Characteristically, the isotherms formed nearly concentric circles about the pole with the temperature increasing poleward. The phase of wave number one is included during the summer period only for purposes of continuity and has no physical significance as the amplitudes of all harmonics were below the noise level. At the autumnal equinox, the variance increased to a weak but significant level, then rose sharply in late November and maintained high values until the vernal equinox. The dashed curve shows that wave number one was the predominate mode throughout most of the winter. During the Northern Hemisphere winter of $1963-64$, the thermal pattern was eccentric to the pole except for a brief period in late December when the thermal regime became bi-polar and thermal wave number two predominated.

One of the most remarkable features of the Northern Hemisphere winter stratosphere is illustrated by the curve showing the phase of thermal wave number one. The ridge of thermal wave number one became situated at about longitude $150 \mathrm{E}$, at a time when the total variance and poleward temperature gradient were very weak, and remained quasi-stationary for the seven months period September 1963 to March 1964. Because of the positive covariance of height and temperature in the middle stratosphere, the warm sector is associated with a geopotential ridge, which develops into a closed anticyclone known as the Aleutian anticyclone. Boville (1960) suggests dynamic processes for the formation of the Aleutian anticyclone, but it is likely that long-wave radiation 
plays a role in keeping the thermal ridge "locked" into position. Observations from TIROS VII of long wave emitted radiation in the 8-12 micron "window" for the month of December 1963 show that the temperature of the radiating surface was some $15^{\circ} \mathrm{C}$ warmer over the Pacific Ocean than over the adjacent continental regions of Siberia and Canada, (Allison et. al. 1967). The warmer lower surface coupled with the winter ozone maximum over the northern Pacific shown by London (1963) could provide relative heating, due to radiative exchange in the 9.6 micron band of ozone, in the Pacific stratosphere as compared with Siberia and Canada. The 8-12 micron observations also show a warm radiating surface over the Atlantic, a region of relatively warm stratospheric temperatures when thermal wave number two is predominate. The ozone concentration is usually a relative minimum over the Atlantic in winter (London 1963) which may explain the greater persistance of wave number one over number two.

An analysis of the phase of geopotential wave number one at $25 \mathrm{mb}$ and latitude $65^{\circ} \mathrm{N}$ by Hare and Boville (1966) showed the ridge to be quasi-stationary at about longitude $120^{\circ} \mathrm{W}$ during three consecutive winters (1958-61). If we assume the phase is about the same at latitude $52^{\circ} \mathrm{N}$, the geostrophic meridional wind and the TIROS derived temperatures of wave number one would be almost exactly in phase so that heat would be transported poleward due to the standing wave. A rough calculation based on the variance values of Hare and Boville (1966) and those of the present study show that the magnitude of the heat transport poleward of $50^{\circ} \mathrm{N}$ during midwinter is sufficient to provide a heating rate of 
about $1^{\circ} \mathrm{C}$ per day. This is of the same order of magnitude as the cooling rate due to longwave radiation. The poleward transfer of heat, toward regions of lower temperatures, implies a conversion from zonal available to eddy available potential energy, the conversion being in the direct, "heat engine" sense (Lorenz, 1955).

Newell (1961, 1963, 1964 a and 1964 b) has shown that poleward heat transfer by horizontal eddies is accompanied by a poleward flux of ozone because poleward moving parcels are sinking relative to surfaces of equal potential temperature whereas equatorward moving parcels tend to rise. The ozone is transferred from solar source regions to lower levels where the ozone is sheltered from solar dissociation. If the polar regions are largely supplied with ozone by quasi-horizontal eddies and the temperature variance curves of Figure 10 are indicative of the degree of eddy activity, then the following inferences can be made: A minimum of ozone at polar latitudes would be expected in the early fall, at which time the increasing eddy activity would begin to transfer ozone poleward where it would be largely stored throughout the winter, reaching a maximum in early spring when the eddies become ineffective. The climatological values compiled by Normand (1953) show that the Arctic ozone concentrations do indeed follow the foregoing schedule.

Figure 11 is the Southern Hemisphere counterpart to Figure 10. The latitude selected was not quite the same as for the Northern Hemisphere because the basic grid was not centered at the equator, but the differences are minor. 
While we do not have appropriate wind data for the Southern Hemisphere we shall assume, as in the Northern Hemisphere that the temperature variance is indicative of the degree of horizontal eddy activity and of the poleward transport of heat and ozone.

The differences between the Hemispheres are readily apparent. The markedly lesser eddy activity is to be expected due to the lack of continental forcing, but equally important is the different timing of the eddies. Whereas in the Northern Hemisphere the eddy activity was large a month before the winter solstice, the eddy activity in the Southern Hemisphere is negligible until over a month after the winter solstice. The lack of early winter eddy activity and related heat transport enables radiative effects to produce much colder winter temperatures in the Antarctic stratosphere (Godson 1963) and the maximum poleward temperature gradient occurs at about the same time as the onset of eddy activity. This picture is again consistent with the observed ozone pattern: The Antarctic ozone is a minimum in winter (Hare and Boville 1966) and begins to increase in late July with the increase in eddy activity. The eddy activity continues for about two months after the vernal equinox, even after the springtime temperature gradient reversal (Fig. 11). This continued poleward transport of ozone even against the temperature gradient is consistent with the occurrence of maximum ozone amounts in late November-early December.

As in the Northern Hemisphere the dashed curve in Figure 11 shows that most of the variance is of wave number one. While wave number one in the 
Southern Hemisphere does not have the stability of its Northern Henisphere counterpart, it is confined to a certain locality as shown by the phase curve of Figure 11. The ridge of thermal wave number one originates south of Australia and travels spasmodically westward to the central South Indian Ocean. It is interesting to note that the warm sector of wave number one remains in the approximate region where tropospheric cyclonic activity is a maximum (Lamb 1959). The summer thermal patterns in the Southern Hemisphere is very similar to that of the Northern Hemisphere with no wave activity in evidence.

The basic differences between the winter circulations of the stratosphere in the two Hemispheres are accentuated by examining the mean and perturbation components of the temperature variance (Fig. 11). The components are computed from seasonal averages of $a_{n}$ and $b_{n}$ of equation (1) and by expressing $a_{n}$ and $b_{n}$ as the sum of a time-mean and a perturbation component:

$$
\begin{aligned}
& a_{n}=\bar{a}_{n}+a_{n}^{\prime} \\
& b_{n}=\bar{b}_{n}+b_{n}^{\prime}
\end{aligned}
$$

where an overbar indicates a seasonal time average and a prime indicates a deviation from the time average. The total variance due to an individual harmonic over a season, $\overline{c_{n}^{2} / 2}$ can be expressed as

$$
\begin{aligned}
\overline{c_{n}^{2} / 2} & \left.=\frac{1}{2} \overline{\left(a_{n}^{2}\right.}+\overline{b_{n}^{2}}\right)+\frac{1}{2} \overline{\left[\left(a_{n}^{\prime 2}\right)+\left(b_{n}^{\prime 2}\right)\right]} \\
& =\bar{c}_{n}^{2} / 2+\overline{c_{n}^{\prime 2}} / 2
\end{aligned}
$$


where $\bar{c}_{n}^{2} / 2$ is the time-mean variance and $\overline{c_{n}^{\prime 2}} / 2$ is the perturbation variance, due to the $\mathrm{n}^{\text {th }}$ harmonic.

Figure 12 compares the results for the first four harmonics for the period December 1963 to February 1964 in the Northern Hemisphere and June to August 1963 in the Southern Hemisphere. M represents the time-mean values and $\mathrm{P}$ stands for the perturbation component. It may be seen that virtually all of the variance is explained by the first two harmonics in each hemisphere.

The time-mean values correspond to standing eddies, those that would appear on a mean seasonal chart. The perturbation values are only a rough approximation to transient eddies since they are derived from 10 day mean charts rather than instantaneous values. The perturbation values, however, should approximate the transient disturbances of a time scale greater than 10 days, which still include the major large-scale disturbances of the stratosphere.

The major difference between the Hemispheres is found in the values of standing eddy number one at latitudes 50 and 60 degrees. In the Northern Hemisphere due to the Aleutian anticyclone, the time-mean value of thermal wave number one is about one order of magnitude greater than the perturbation component. In the Southern Hemisphere the perturbation component of wave number one is larger than the time-mean component. The appearance of a timemean component of wave number one in the Southern Hemisphere, though small, is due to the warm portion of the wave remaining in one sector of the hemisphere throughout the winter. It is interesting that the perturbation components of 
waves one and two are similar in both hemispheres for equivalent laiitudes, and at latitude $40^{\circ}$, the total wave structure is nearly indentical.

\section{CONCLUSIONS}

The observational results, which are limited to a temperature field smoothed with altitude as well as with time and cover only a period of one seasonal cycle, do not permit an exhaustive analysis of climatological behavior of the stratosphere. They do illustrate, however, that satellite radiometry can provide a significant description of stratospheric dynamics in the absence of other, more conventional, observations.

We conclude from the variations in the "quasi-global" patterns of equivalent blackbody temperatures that the seasonal temperature cycle of the stratosphere in both Hemispheres is exactly in phase with the variation of the declination of the sun. These temperature fields, especially the variance of temperature along high latitude circles, are indicative of large scale horizontal eddies during winter in both Hemispheres. The eddies, which are probably responsible for transporting heat and ozone to high latitudes, seem to develop in preferred locations around warm air cells over the Aleutian Islands and over Australia in the respective Hemispheres. Wave number one dominates both of these eddies. The one in the Northern Hemisphere is considerably more intense and stationary than its Southern Hemisphere counterpart. In addition to differences in intensity and persistence there is another major difference between the eddy circulation in the two Hemispheres: In both Hemispheres eddy activity begins to increase 
at the atumnal equinox and intensifies abruptly about two months after that, but in the Northern Hemisphere this activity ceases abruptly just before the vernal equinox while in the Southern Hemisphere it does not subside until about two months later. In both Hemispheres large scale eddy circulation is absent during the summer months. Because of the greater poleward heat transport during the winter by the horizontal eddies in the Northern Hemisphere than in the Southern Hemisphere, temperatures in the tropics follow an annual variation which is in phase with the Northern Hemisphere cycle. Tropical temperatures are appreciably higher during June than during December. 


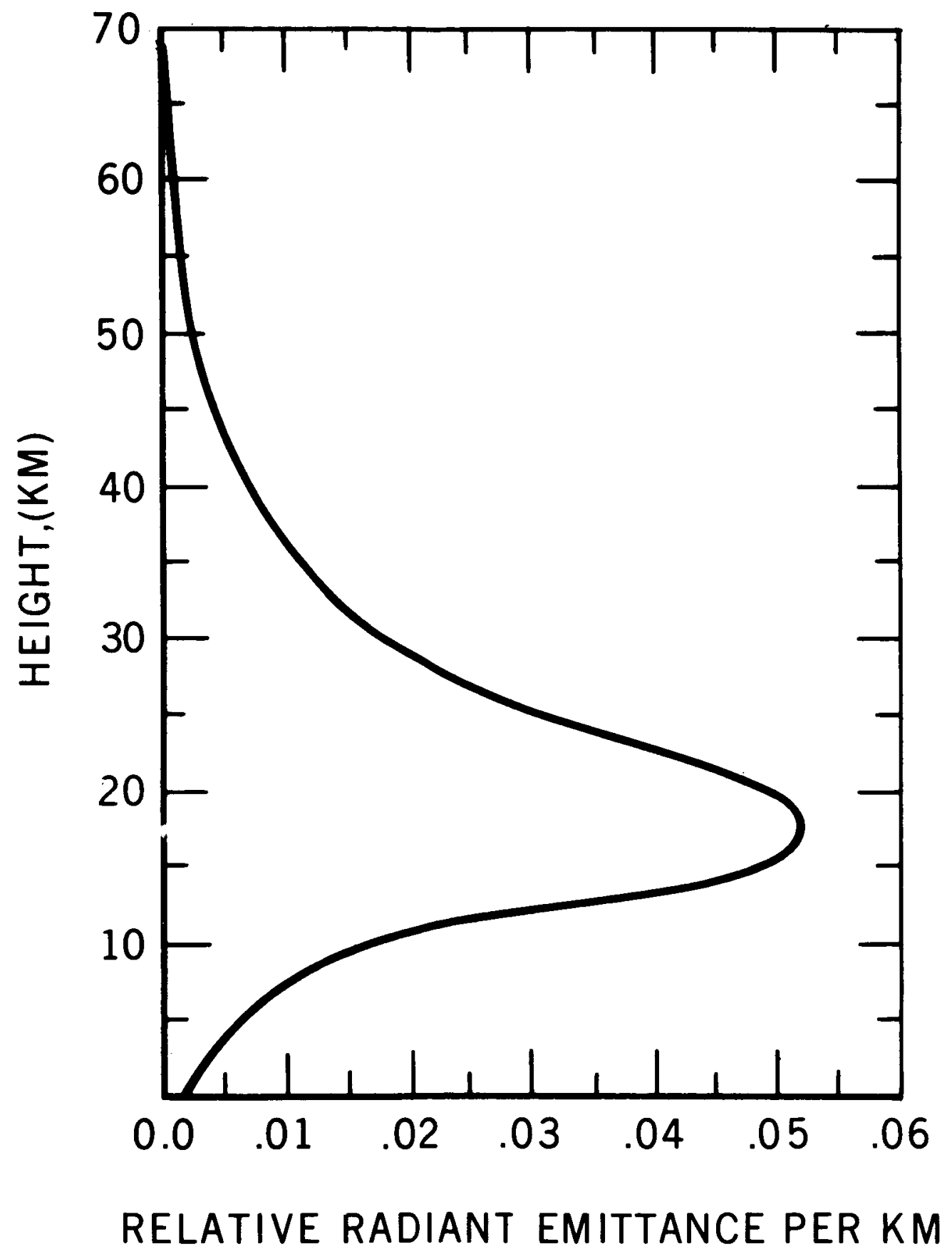

Figure 1-Variation with height of computed ratio of radiant emittance for one kilometer height intervals to total radiant emittance of the atmosphere, observable by TIROS VII in the 15 micron spectral region. Computation is based on an atmospheric temperature profile of the 1962 U. S. Standard Atmosphere. 


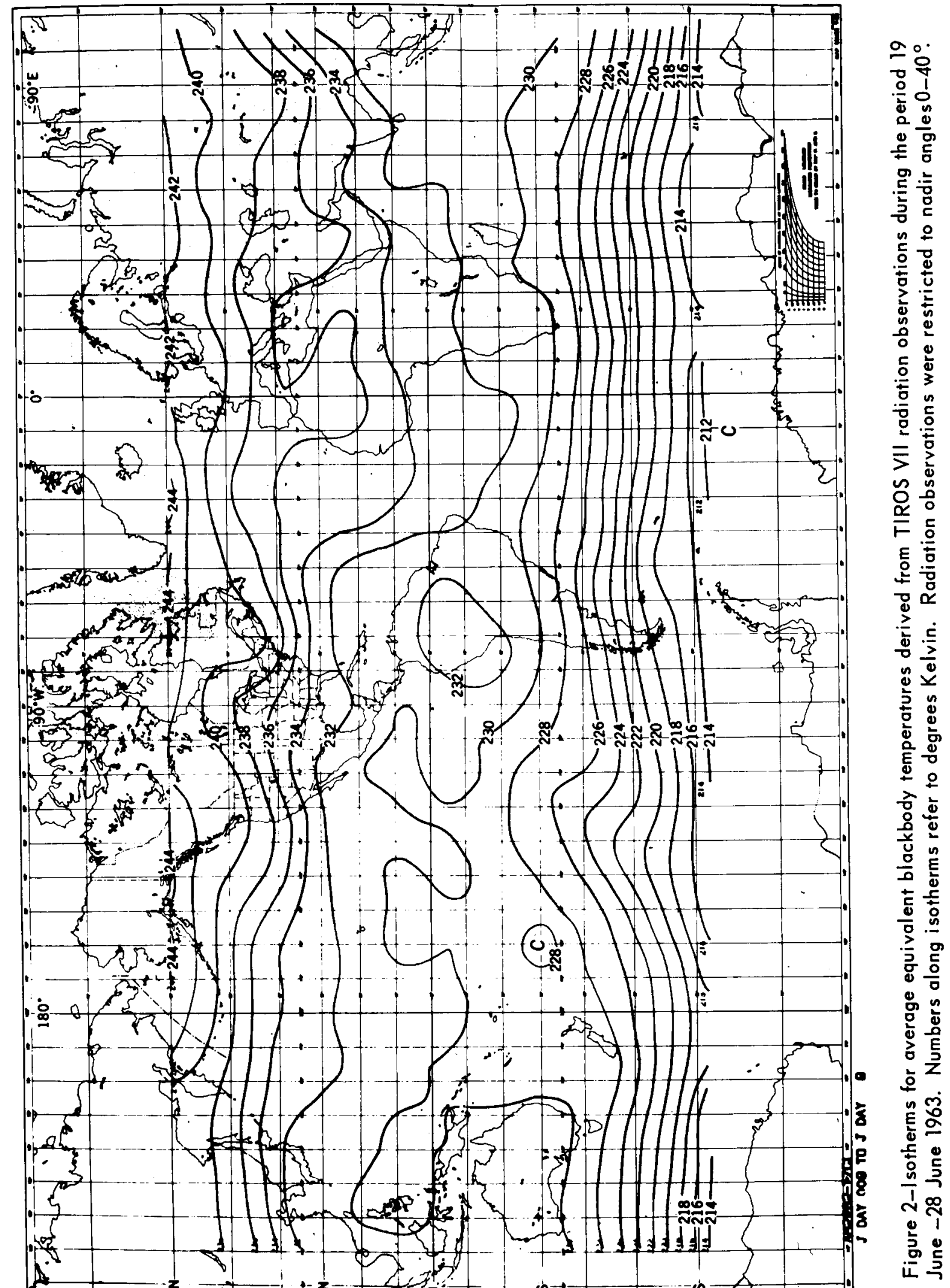






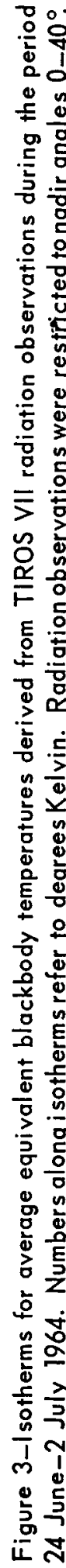




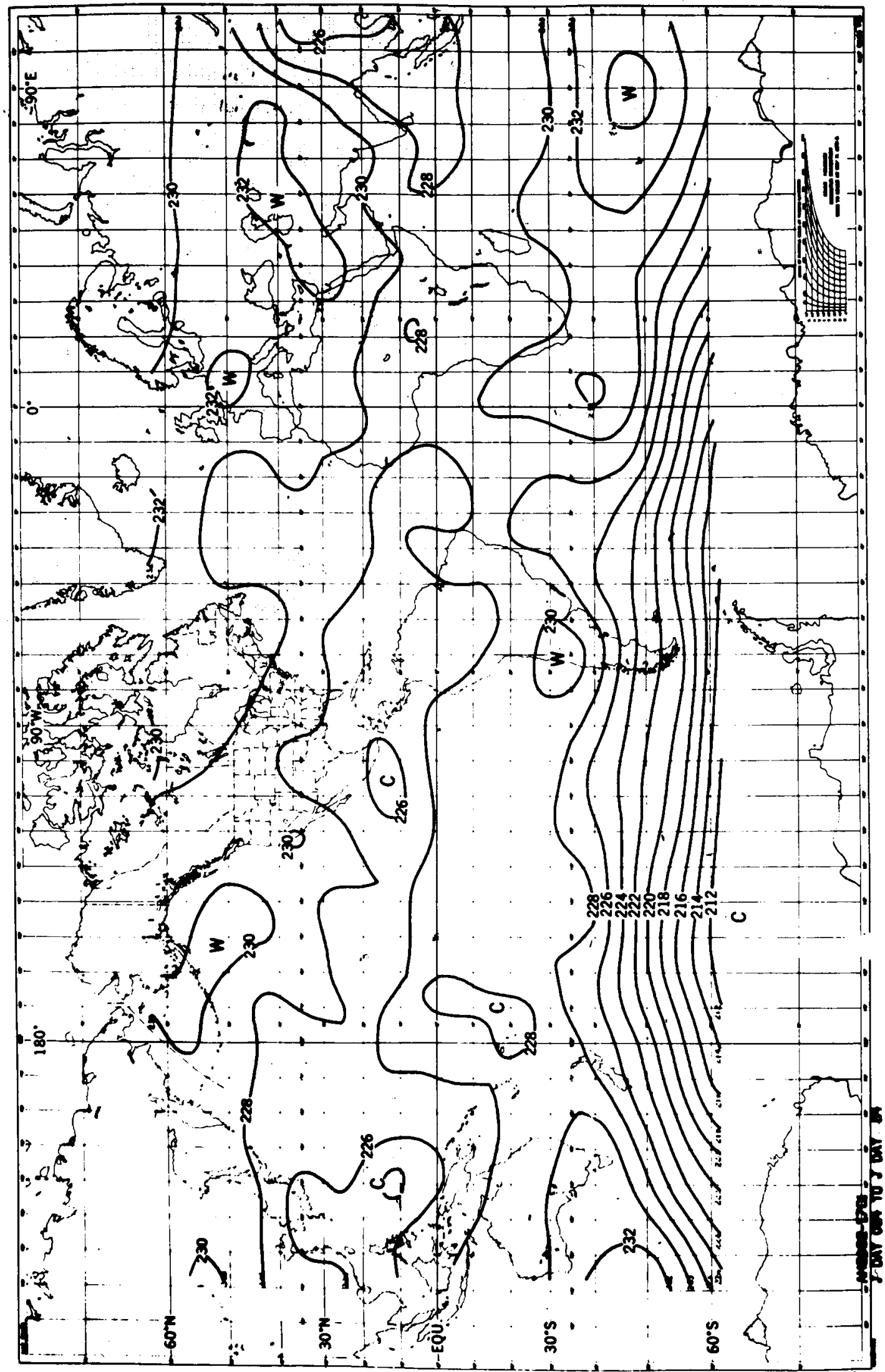

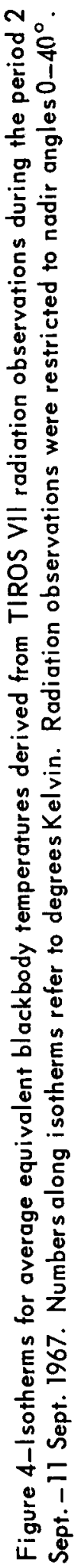




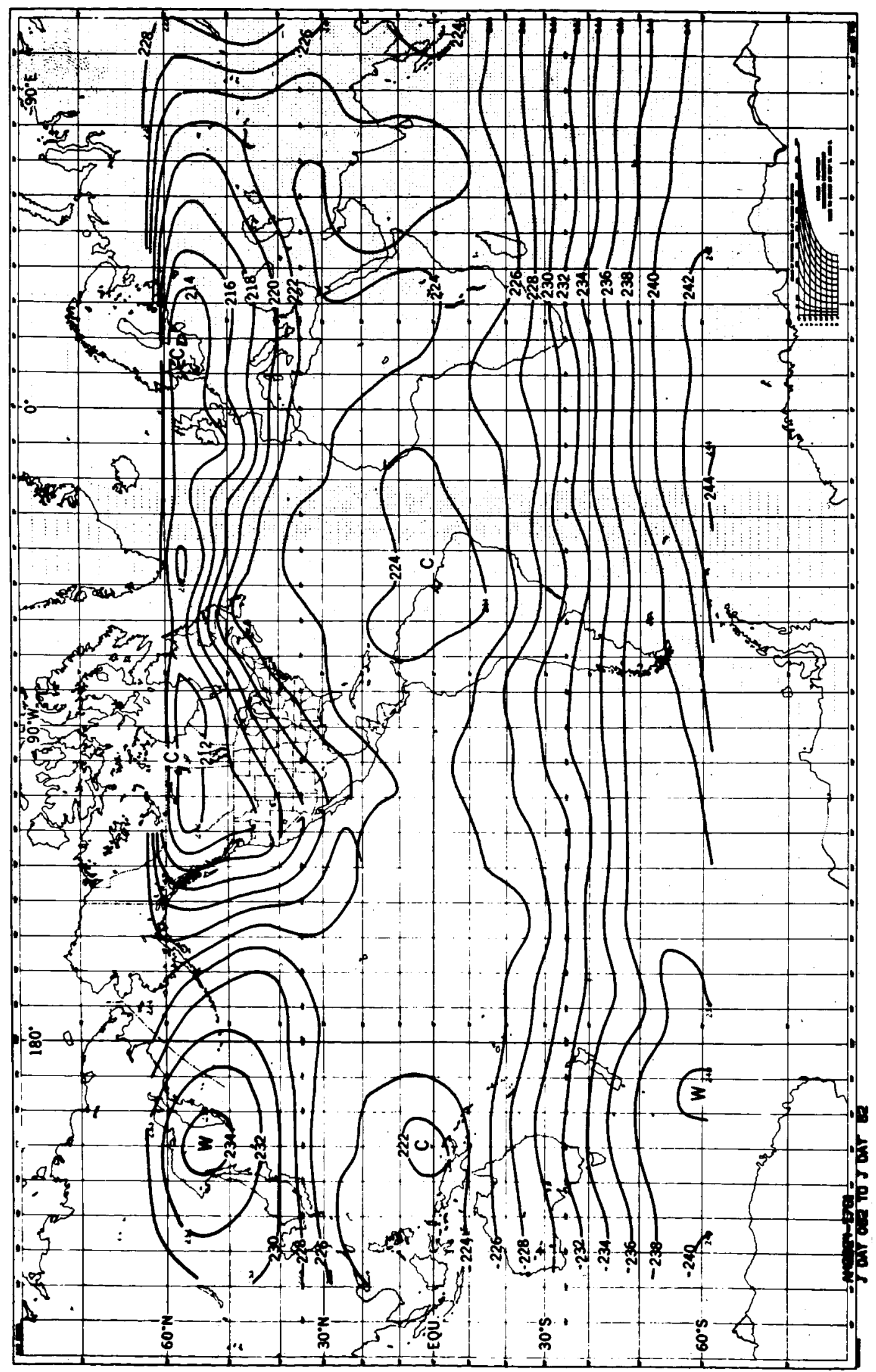

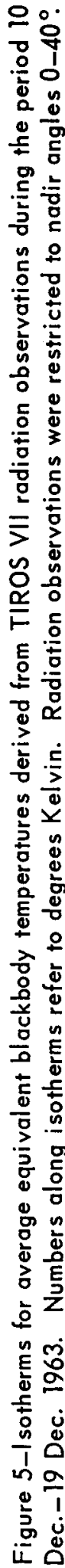




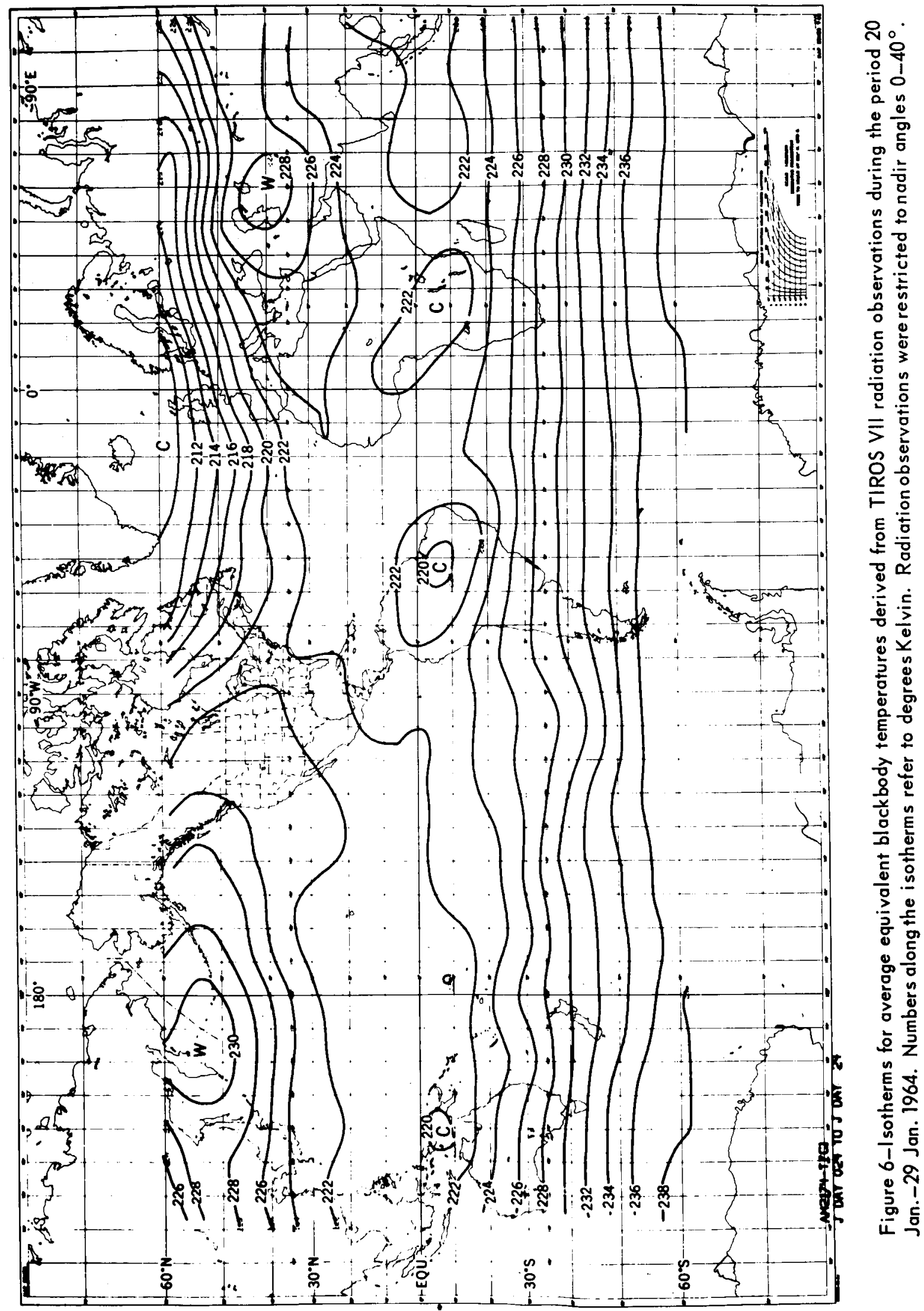




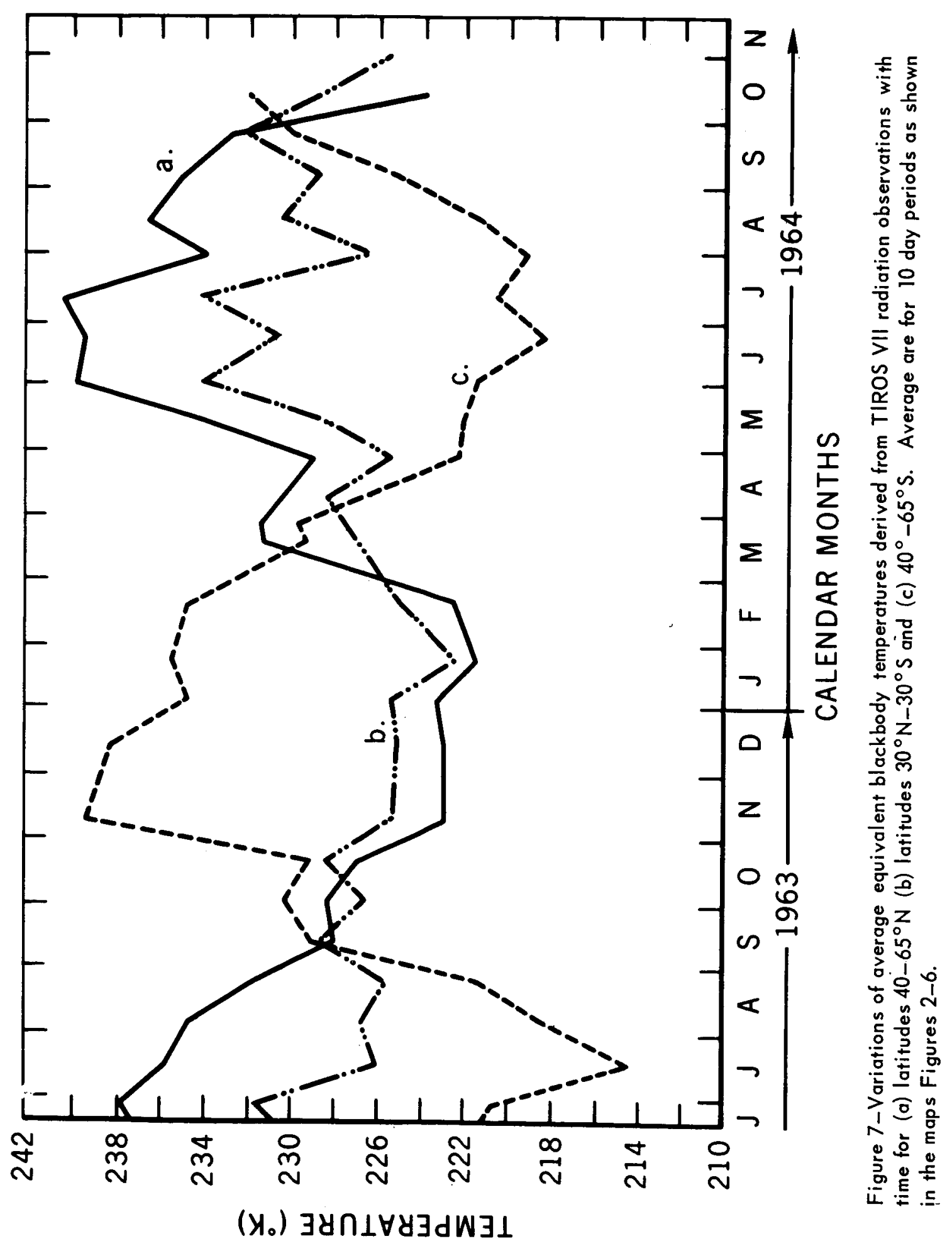




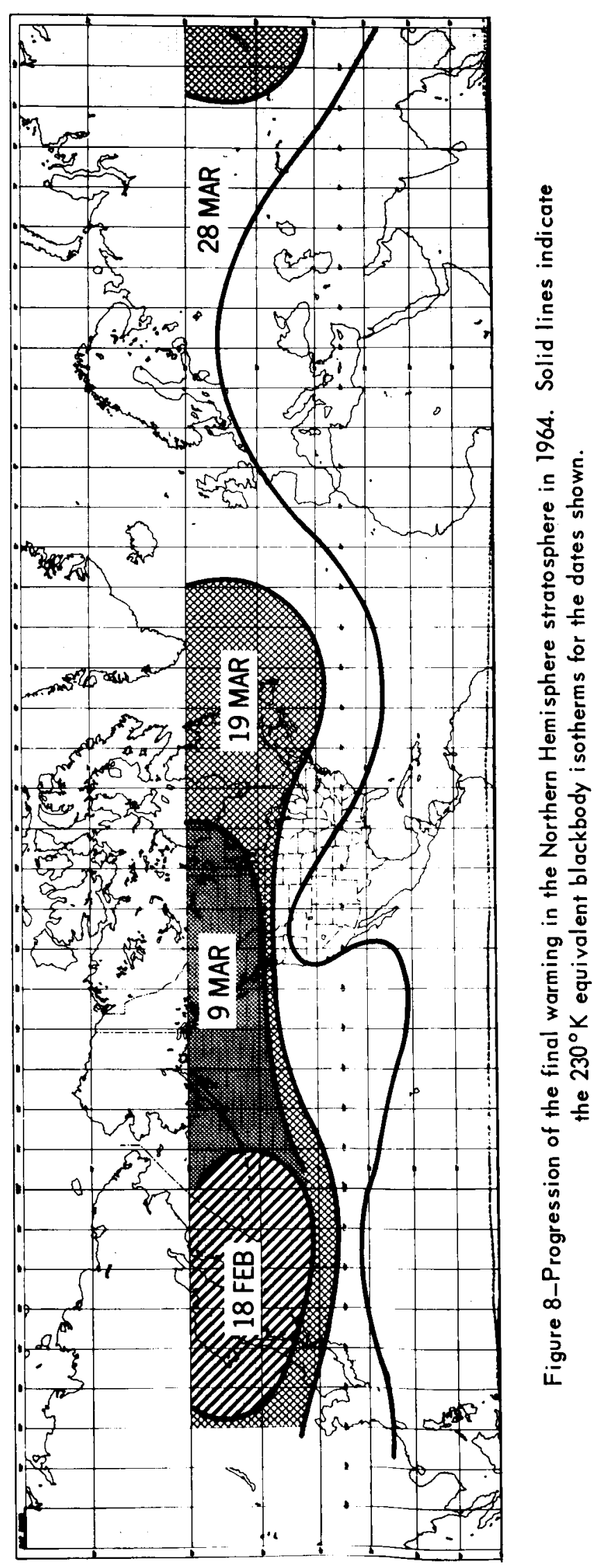









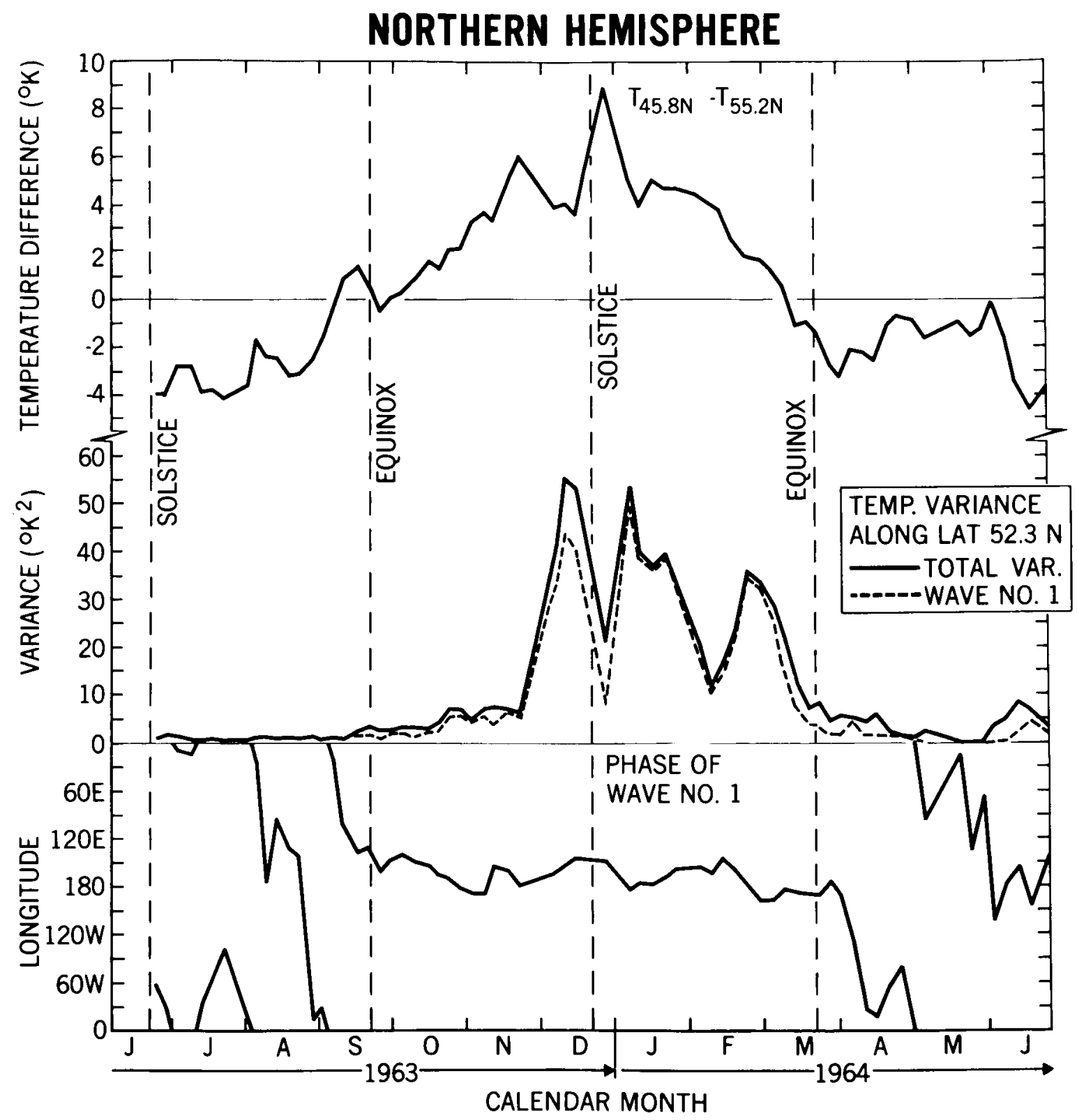

Figure 10-Top: Mean zonal equivalent blackbody temperature difference between latitudes $45.8^{\circ} \mathrm{N}$ and $55.2^{\circ} \mathrm{N}$. Center: Total equivalent blackbody temperature variance (solid) and variance of first harmonic (dashed) along latitude $52.3^{\circ} \mathrm{N}$. Bottom: Longitudinal position of the ridge of the first harmonic along latitude $52.3^{\circ} \mathrm{N}$. 


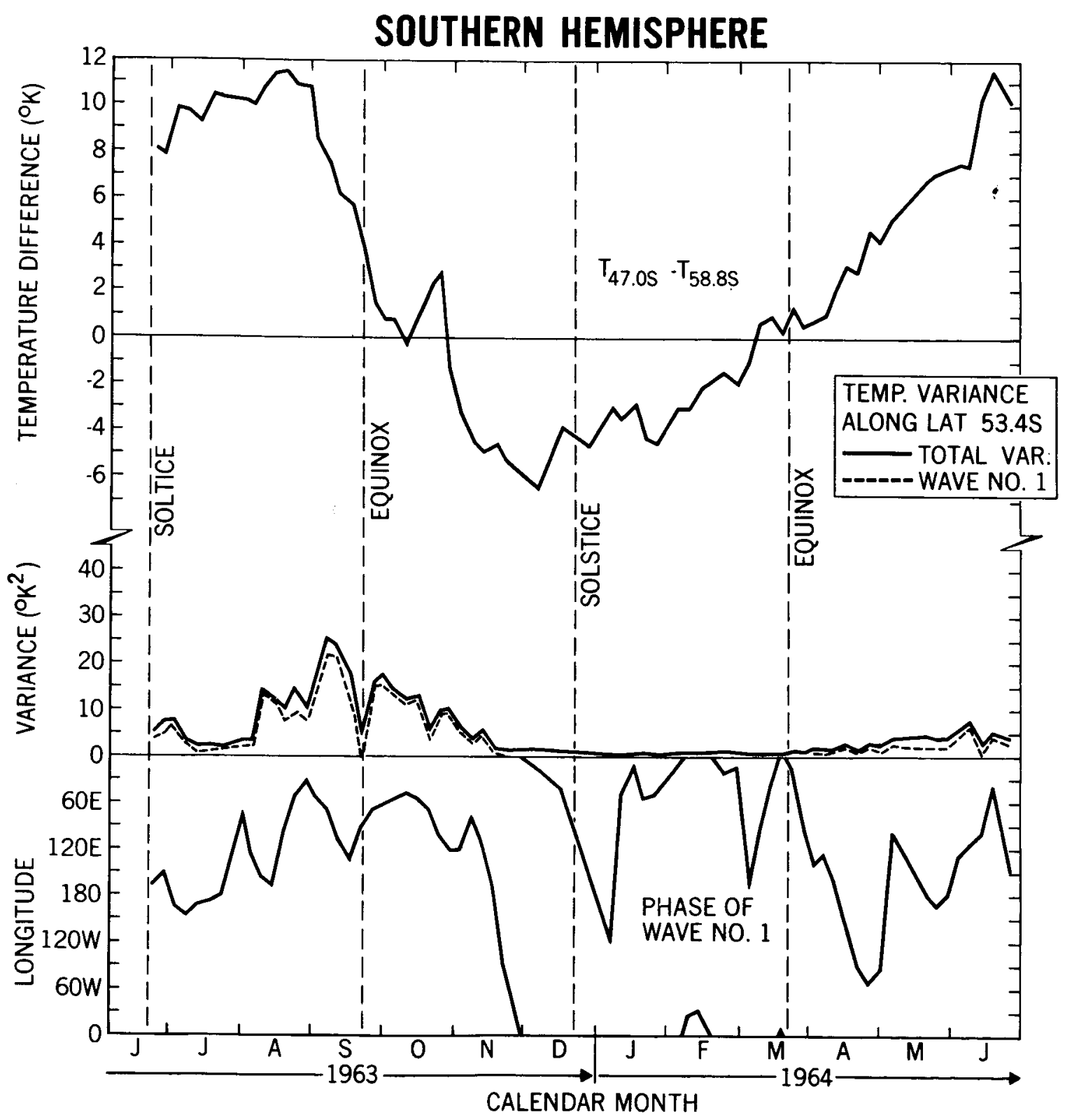

Figure 11-Top: Mean zonal equivalent blackbody temperature difference between latitudes $47.0^{\circ} \mathrm{S}$ and $58.8^{\circ} \mathrm{S}$. Center: Total equivalent blackbody temperature variance (solid) and variance of first harmonic (dashed) along latitude $53.4^{\circ} \mathrm{S}$. Bottom: Longitudinal position of the ridge of the first harmonic along latitude $53.4^{\circ} \mathrm{S}$. 


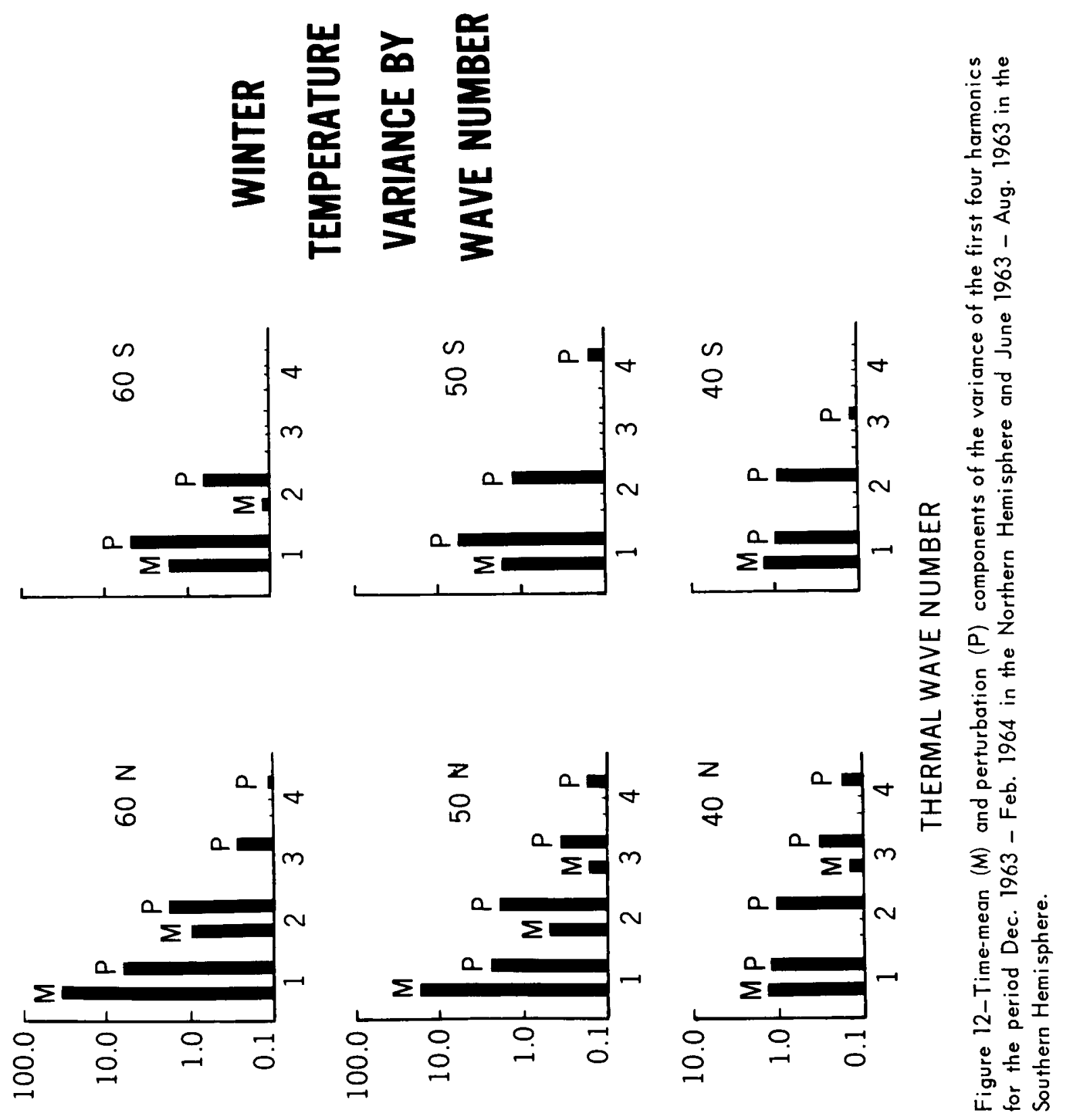

$\left(2 y_{0}\right) \quad \exists \supset N \forall I Y \forall \wedge \exists y \cap \perp \forall Y \exists d W \exists \perp$ 


\section{REFERENCES}

Allison, L. J., E. R. Kreins, F. A. Godshall, and G. Warnecke: Global Circulation Characteristics Reflected in TIROS VII Radiometric Measurements. NASA Report, Goddard Space Flight Center, Greenbelt, Md. In preparation.

Boville, B. W., 1960: The Aleutian stratospheric anticyclone., J. Meteor, 17, $329-336$.

Godson, W. L., 1963: A comparison of middle-stratospheric behavior in the Arctic and Antarctic with special reference to final warmings. Met. Abh., $\underline{36}, 161-206$.

Hare, F. K., and B. W. Boville, 1966: The polar circulations. The Circulation in the Stratosphere, Mesosphere and Lower Thermosphere, World Meteorological Organization Technical Note No. 70, 43-78, Geneva, Switzerland.

Kennedy, M. S., 1966: An Atlas of Stratospheric Mean-Isotherms Derived from TIROS VII Observations., NASA X-622-66-307, Goddard Space Flight Center, Greenbelt, Md., July 1966.

Lamb, H. H., 1959: The southern westerlies: a preliminary survey; main characteristics and apparent associations. Quart. J.R. Meteor. Soc., 85, 1-23.

London, J., 1963: The distribution of total ozone in the Northern Hemisphere. Beitr. Phys. Atm., 36, 254-263.

Lorenz, E. N., 1955: Available potential energy and the maintenance of the general circulation, Tellus, $\underline{7}, 157-167$. 
Newell, R. E., 1961: The transport of trace substances in the atmosphere and their implications for the general circulation of the stratosphere. Geofis, Pura e Appl., 49, 137-158.

Newell, R. E., 1963: Transfer through the tropopause and within the stratosphere. Quart. J. R. meteor. Soc., 89, 167.

Newell, R. E., 1964a: Stratospheric energetics and mass transport. Pure and Appl. Geophys., 58, 145-156.

Newell, R. E., 1964b: Further Ozone transport calculations and the spring maximum in ozone amount. Pure and Appl. Geophys., 59, 191-206.

Newell, R. E., 1965: A review of studies of eddy fluxes in the stratosphere and mesosphere. Report No. 12, Plan. Circ. Proj. of Meteor., MIT, 53p.

Nordberg, W., W. R. Bandeen, G. Warnecke, and V. G. Kunde, 1965: Stratospheric Temperature Patterns Based on Radiometric Measurements from the TIROS VII Satellite, pp. 782-809, Space Research V., Edited by P. Mueller, North Holland Publishing Company., Amsterdam.

Nordberg, W., A. W. McCulloch, L. L. Foshee and W. R. Bandeen, 1966: Preliminary Results from Nimbus II, Bull. of Am. Met. Soc., Vol. 47, No. 11, November $1966,857-872$.

Normand, Sir Charles, 1953: Atmospheric ozone and the upper air conditions, Quart. J. R. Meteor. Soc., 79, 39-50.

Oort, A. H., 1963: On the energy cycle in the lower stratosphere, Report No. 9, Plan. Circ. Proj. of Meteor., MIT, p. 122. 
Palmer, C. A. and R. C. Taylor, 1960: The vernal breakdown of the stratospheric cyclone over the South Pole, J. Geophys. Res., 65, 3319-3329.

Reed, R. J., J. L. Wolfe, and H. Nishimoto, 1963: A spectral analysis of the energetics of the stratospheric sudden warming of early 1957. J. Atmos. Sci., $20,256-275$.

Saltzman, B., 1957: Equations governing the energetics of the larger scales of atmospheric turbulence in the domain of wave number. J. Meteor., 14, $513-523$.

Staff Members, 1964: TIROS VII Radiation Data Catalog and User's Manual, Vol. I, Goddard Space Flight Center, Greenbelt, Md., 30 September, 1964, $256 \mathrm{pp}$.

Teweles, S., 1963: Spectral aspects of the stratospheric circulation during the IGY. Report No. 8, Plan. Circ. Proj. of Meteor., MIT, 191 p.

U. S. Standard Atmosphere, 1962: U. S. Government Printing Office, Washington D.C., December 1962, p. 278 .

Van Miegham, J., 1963: New aspects of the general circulation of the stratosphere and mesosphere., Met. Abh., 36, $\underline{5}$.

Wilson, C. V. and W. L. Godson, 1963: The structure of the arctic winter stratosphere over a 10 year period. Quart. J. R. Meteor. Soc., 89, 205224 . 